\title{
Scott Pilgrim vs the future of comics publishing
}

Padmini Ray Murray, University of Stirling

\begin{abstract}
Publishers have always been keen to maximize the multimedia potential of their products, and are increasingly eager to make the most of the opportunities afforded to them by digital platforms and technologies. While this sort of treatment is ubiquitous for those intellectual properties belonging to industry behemoths Marvel and DC, it is unusual for those published by smaller independent presses to receive similar consideration.

However, Bryan Lee O Malley's comic book series Scott Pilgrim despite its modest, independently published beginnings, was bought by Fourth Estate and then made into a major motion picture in 2010 , the release of which was accompanied by a mobile phone
\end{abstract} app. This article will explore how the consequences of commercial decisions taken by Fourth Estate and the creators of the app affect the reception of the comic, and is informed by original interviews with the publisher and app creator. It will pay particular attention to the significance of content contained within the print comics that is not contained within the app. My examination will draw on Gerard Genette's definition of the paratext and how it locates the print comic within a creative economy that privileges a DIY practice - demonstrating an allegiance, for example, to webcomic creation, a direct transaction between creator and consumer that bypasses the producer entirely. This analysis will be coupled with an investigation of how the migration of print content to app affects the reading of the comic, and is augmented by a survey of comics readers who are used to reading digital content on-screen. I argue that not only does the intervention of digital technology transform the aesthetic product, the commercial motivations of the 
publisher/producer are inextricable from our understanding of the comic as artefact, thus emphasizing the need for a more cultural materialist approach in comics studies as a discipline.

\section{Keywords}

epitext

Scott Pilgrim

videogames

transmedia

Henry Jenkins

Gerard Genette

webcomics

paracontent

Meet Scott Pilgrim. He is a 23-year-old Toronto-based, slacker-dropout, emotionally arrested man-child who falls for a 'roller-blading subspace American ninja amazon dot com delivery girl' (O’Malley 2003) called Ramona Flowers. Bryan Lee O’ Malley’s sixvolume series chronicles the battles that inflect the highs and lows of Scott and Ramona's romance, drawing liberally on a manga-tinged video game aesthetic that clearly struck a chord with readers. The series had one million copies in print by 2010 in North America alone, and made it to the New York Times bestseller list (The Beat 2010). Unusually for an indie comic (Scott Pilgrim was published by Oni Press), it generated a number of adaptations - a film, a video game, an animation and a mobile phone app. Henry Jenkins defines transmedia storytelling as 'a process where integral elements of a fiction get 
dispersed systematically across multiple delivery channels for the purpose of creating a unified and coordinated entertainment experience' (2007). Jenkins' seminal work cites the Wachowski brothers' The Matrix as an example of transmedia storytelling: 'entertainment for the age of media convergence, integrating multiple texts to create a narrative so large that it cannot be contained within a single medium' (2006b). The Wachowski brothers used teaser trailers and treasure hunts across media forms to great effect to pique viewers' interests. However, O'Malley's own involvement in the adaptations of his work is less significant than the impact of the transmediality at the heart of the text itself, which shaped its extension and reception over a variety of media and delivery formats. As this article will demonstrate, this makes Scott Pilgrim an appropriate object lesson to demonstrate the ramifications that remediation and media convergence have for the future of comics publishing.

Scott Pilgrim at its heart maps a blossoming romantic relationship, but its USP consists of how it meshes a naturalistic narrative and visual style with surreal episodes staged in a video game universe, which gives the comic an almost magic realist feel. Scott Pilgrim is a text that embodies transmediality, its very premise assuming at least a notional understanding of video games. In order to be with Ramona, Scott Pilgrim has to defeat her seven evil exes in elaborately staged battles that draw liberally on a vocabulary familiar to gamers - an economy where skills, resources and tenacity are embodied in material objects such as swords, gold coins and levels, and without this awareness, understanding of the comic is notionally incomplete. However, it is crucial to emphasize that this understanding is not at the level of narrative, but rather at that of narrative form.

\section{Narrative logic of video games}


The extent to which O'Malley follows the narrative logic of the video game is evident from how closely the comic's story arc imitates the framework of a game. Celia Pearce describes a game as follows:

structured framework for spontaneous play consisting of

--A goal (and a variety of related sub-goals)

--Obstacles (designed to prevent you from obtaining your goal)

--Resources (to assist you in obtaining your goal)

--Penalties (for failing to overcome obstacles, often in the form of more obstacles)

--Information

1) Known to all players and the game

2) Known to individual players (e.g. a hand of cards)

3) Known only to the game

4) Progressive information (moves from one state of knowledge to another). (2002: 112)

This framework is closely mimicked by the narrative action of the Scott Pilgrim series where:

--Scott's goal is to be with Ramona (sub-goals: to defeat her evil exes)

--Obstacles: the afore-mentioned evil exes (designed to prevent you from obtaining your goal)

--Resources: this is where O'Malley's narrative demonstrates some sophistication - - 
while the usual video game tools of coins, swords and extra lives feature, O'Malley treats them as metaphors standing in for virtues such as courage, loyalty and initiative that inflect Scott's interpersonal relationships both with Ramona and his friends, who make up the cast of characters who populate the book. His penalties, similarly, have more profound manifestations, such as depression, abandonment and misunderstandings that cause Scott to rethink his personal path and choices, resulting in a more serious chronicle that belies the playfulness and innocence of the medium. Manga is often characterized by nostalgia for youth, ${ }^{1}$ and often portrays growing up as a halcyon experience, but O'Malley's more knowing and darker treatment of Scott's coming of age is embodied by the heavily allegorical Nega-Scott, his evil doppelganger with whom Scott's fate ultimately lies. The information element of the game can be extended to the moments where O'Malley resorts to breaking the fourth wall, alluding to the reader's experience through metatextual devices. For example, Scott says to Ramona on their first date, 'Well, my last job is a really long story, filled with sighs. Maybe we can get into it in a later volume' (O'Malley 2004).

This allusiveness to gaming culture was not new - both Penny Arcade and $P v P$ were long-running webcomics offering commentary and storylines based on video game culture. The geek demographic these comics appealed to enjoyed this allusive play as injokes and recognition of stereotypes, and the considerable overlap between comic readers and gamers, which made this formula more effective. As the popularity of these webcomics attests, this demographic were early adopters of paying for and reading online content, compared to the mainstream trade fiction readers.

\section{Scott Pilgrim's little (online) life: Webcomics and their paratexts}


The commercial trajectory of the online comic is quite divergent from that of mainstream trade book publishing, the latter of which is only now fully realizing the potential of selfpublishing on or through the Internet. Webcomics (which, for the purpose of this article are being defined as comics that are published first on the Internet) emerged as a consequence of comic creators wishing to indulge their artistic freedom in a climate where increasingly risk-averse comic publishers were unwilling to take a chance on more adventurous approaches to comic making. The webcomic community is governed by different business values than the print comic business - relying on 'word of mouse' through blogs, memes and social networking sites to gather an audience. The financial viability of webcomics is not assured; more often than not comic creators make more money on merchandise associated with the comic (sometimes, in a strange reversal, this may be the print version of the webcomic) and advertising, rather than the comic itself, which is often free to view on the Internet. Some subscription models do succeed, such as the long-running Modern Tales website, founded by Joey Manley in 2002, which aggregates content from various creators, and is noteworthy for actually making a profit despite its very low subscription rate of \$2.95 a month (Modern Tales 2012).

Migrating their work online of course permitted creators to have more freedom both creatively and in terms of distribution, but it also allowed them to create intimate relationships with their readerships that often grew and sustained their support. Gerard Genette's definition of the paratext might help to provide a theoretical vocabulary that describes these author-audience interactions. Paratexts are defined as 'those liminal devices and conventions, both within and outside the book, that form part of the complex mediation between book, author, publisher and reader: titles, forewords, epigraphs and 
publishers' jacket copy are part of a book's private and public history' (Genette [1997] 2007). Webcomics are usually supported by a paratextual web of author blogging, sketches and progress reports. This encourages a level of interaction with the comic's readers that may result in generating sales of merchandise or donations, but more often than not, the pay-off is not financial. Genette's definition assumes that the book's public history comes into being as soon as the circumstances of publication are realized, such as advertisements, advance information sheets and inclusion in catalogues, all of which are underpinned by the prospect of commercial exchange ([1997] 2007). However, when transposed to a digital economy, such definitions of public and private become somewhat muddled, especially with regard to the business of comics. The 'epitext' is that paratextual material that is "not materially appended to the text within the same volume, but circulating, as it were, freely, in a virtually limitless physical and social space' (Genette [1997] 2007: 344). With the advent of the Internet, many comics creators have chosen to reveal their artistic process online, often blogging about their method in detail, and communicating with their readers regarding creative decisions made, thus creating an epitextual archive. However, these communications do not, at least directly, implicate any financial consequences. Accordingly, if the material that O’Malley put up before and during the lifespan of Scott Pilgrim in the form of blogposts, sketches and photographs could be considered epitextual, what are the commercial implications of such material?

In interviews, O’Malley makes no secret of how important the digital space was for his growth as an artist:

In my late teens I first got on the internet (in like 1996-97) and made a few 
friends who were doing the same thing and started to see it as a potential way to reach an audience. I started putting my half assed comics online and running a site called 'impromanga' where one artist would write \& draw the beginning of a story and then pass it off to another artist, and so on and so forth. (This wasn't initially my idea, but I took over from the site's creator and I think did a pretty decent job expanding on the concept and making it a viable and fun thing for online wannabe comic artists in the late 90s) I tried to draw a chapter of each story that came through the site, attempting lots of different genres and art styles [...] Despite my whole web-based existence in the late 90 s, I never really 'started a webcomic'. My basic problem was I couldn’t commit. (2012)

The legacy of these practices can be found in the paratextual material of the books, which feature the work of other artists drawing interpretations of O'Malley's characters - a modification of the manga tradition of tribute art, known as Doujinshi. These situate the comics within the creative economy of the webcomic, despite their status as material rather than digital artefacts.

However, despite the formative role the Internet played in O'Malley's growth as a comic creator, he was less than eager to create webcomics:

I think the last time we talked I was more interested in webcomics, but they're still not really taken seriously. Like, if I did a webcomic, maybe a million people would read it, but the New York Times would never review it. 
So I don't know. They still don't have that legitimacy. I'm drawn to the format, I'm just not sure how to make it work. Maybe just by virtue of having someone who did 'Scott Pilgrim' doing a webcomic, by brute force that would legitimize it slightly. I don’t know. (Hudson 2010)

\section{Local contexts and epitextuality}

Despite its fantastical video game departures, Scott Pilgrim is strongly tied to its local context both in terms of content and its material conditions of production, which is best exemplified by O’Malley's zine-like production The Annotated Pilgrim (2007). This 30page hand-stapled booklet contains notes on the first two volumes, which include snippets of the original script, storyboards, reference photos and sketches, most of which were originally posted online on O'Malley's Livejournal. The result is somewhat like a DVD commentary on a film, where O'Malley freezes the action of the comic to justify artistic choices made, or the personal resonance of certain moments. 'Transmedia storytelling, then, has the dual quality of being both market and non-market motivated, or to put it the other way around it is driven by both artistic and non-artistic motivation' (Bolin 2011: 91) The 'story' being extended here is both Scott's and O'Malley's, and The Annotated Pilgrim can be seen as a consolidation of the latter's epitextual online activity that promotes the book as well as involving the audience in the process. With a print run of 250, and its ephemeral format, The Annotated Pilgrim was intended to be sold at the Toronto Comics Art Festival, as well as local comic book mecca The Beguiling (where O’Malley once worked). Bob Spiegel, an urban geographer who created a Scott Pilgrim map by cross-referencing locations in the books and Google Maps, said: 
I love Scott Pilgrim for any number of reasons, but what really sets it apart from most other comics is that it takes place *somewhere*. Other comics like Batman and Superman take place in a made-up city [...] It really is tied in to our urban fabric. (Spiegel cited in Grainger 2010)

This 'local' characteristic becomes increasingly more significant in the context of the numerous formats Scott Pilgrim is adapted into, as the following sections will demonstrate.

\section{The film, the app: The effects of remediation}

Scott Pilgrim was optioned for a film in 2005 when O'Malley had just about finished the second volume. The film and the comic book series had an oddly symbiotic relationship as they progressed simultaneously - Edgar Wright, the director of the film, was keen that O’Malley be involved with the screenplay from the very outset, and consequently some of the content from the screenplay found its way into Volumes 4 and 5 (Tabor 2010). However, given the pace of the film's production and O'Malley's progress on the sixth volume, there was not going to be any overlap between the content, and both Wright and O’Malley decided early on that the endings would be different.

Mark Richards, a commissioning editor for Fourth Estate (United Kingdom), encountered Scott Pilgrim when he met the literary agent selling foreign rights for Oni Press, and realized its commercial local potential given that the film was already in production and had significant British links. In an interview he said, 'I don't read comics or graphic novels but I really really liked [the books] - I thought they were smart and funny even though I was uninitiated in the genre - if I had enjoyed [them], they would be 
accessible and enjoyable for other people' (Richards 2011). However, Richards makes it clear that he would have been more reluctant to invest in the book if the film had not been in the offing, as the press activity surrounding the film could be used for leverage, thus making it a solid, though slightly risky, investment.

Fourth Estate had bought only one graphic novel previously, Marisa Acocella Marchetto's Cancer Vixen, and it had sold badly despite the publisher's reputation for supporting 'off the wall' titles. The first five volumes of Scott Pilgrim had been distributed by Titan in the United Kingdom previously, which meant it was already available in specialist comic book shops, but Fourth Estate republished the series along with the sixth volume in 2010 . The latter sold very well with the release of the film, and then witnessed a further spike in sales with the DVD release later on in the year. The backing of Fourth Estate meant that the books had wider exposure in high street bookshops such as Waterstones, HMV and Amazon, and its legitimacy as a literary imprint possibly guaranteed it higher critical and cultural visibility (Richards 2011).

Publishers base marketing decisions on assumptions that are informed by segmenting the market in order to recognize the appropriate demographic for the book they are trying to sell. Fourth Estate recognized that Scott Pilgrim's readers, given the books' allegiance to video game culture, would be digitally savvy, and thus creating an app seemed like a perfect opportunity to cater to its potential readership. The decision to develop an app for the book was a revolutionary one for an independent comic, and was covered widely in the booktrade, technology and comics press. The first volume was to be released for the iPhone and iPad in May 2010, with each volume being released thereafter, building up to the release of the sixth volume and the film in August. Robot 
Media worked in conjunction to create the app, which contained original new artwork, social networking tools for fans, and enhanced features such as vibrations and sound effects that were triggered during fight scenes in the book.

Fourth Estate and Robot Media, the creators of the app, felt that the remediation of the comic book to mobile phone app demanded a degree of innovation that would distinguish it from a mere e-book. The app's social networking aspect facilitated a rolling comments page, used by readers to discuss the series as well as the internal game, which allowed users to discover 'hidden secrets' in the game. The pricing differential between the print edition and the app was quite significant, as the RRP of the print book was $£ 7.99$ and the app $£ 3.99$. Hermes Pique, the founder of Robot Media, points out that such a pricing strategy was necessary as the assumptions that underpin comics marketing, which caters to a niche market, were no longer valid as the app was 'not competing against other comics [but] competing against other apps' (12 July 2011 interview). The app was moderately successful, with approximately 3000 downloads, but was unlikely to cannibalize print sales, which totalled approximately $30,000-50,000$ per volume.

Readers have complained about how reading digital versions can often diminish the quality of colour and detail that can be found on printed high-quality paper, and that comics intended for one medium often fails in another. Fourth Estate chose to go ahead with creating the Scott Pilgrim app as they felt that it was less likely to lose quality in reproduction due to being originally black and white. Robot Media chose to tackle this by reinterpreting the physical boundaries of the printed page onto what comics pioneer and scholar Scott McCloud has called a theoretically infinite (digital) canvas (2009) - using the device as a window to view the panels, which transition kinetically. 
Jeff Thoss pits the comic book itself against the film version, and comments on how each competes to 'deny their actual mediality to engage in a competition of simulating yet another medium - the video game' (Reinerth 2011). The app too (which Thoss does not touch upon in his discussion) is destined to fall short of the mimetic benchmark set by the video game as media form, for despite its sensory enhancements, it is limited in its interactive potential despite the puzzle game embedded in the text by way of clues and hints. It also demonstrates the dilemma of remediating comic books to apps, requiring both a porting of text and image, as the app can only replicate the book's ability to engage the reader's imagination on first contact. (A similar example would be a frameby-frame film adaptation of a comic book, such as Frank Miller's Sin City.)

O’Malley's own reaction to the app possibly sums up the reaction of many readers:

We're doing Scott Pilgrim on the iPad. But I don't know how it'll work. I don't have an iPad. I have a PSP and I downloaded Matt Fraction's first issue of ‘[Invincible] Iron Man’ on it, and I don’t really like reading a comic on that tiny screen... The apps for that, they read it for you, and that takes away an element of comics to have it scrolling around. And then I don't think it's the same medium anymore. (Hudson 2010)

The dynamic comic violates one of the comic book form's unique features: its multi-image structure that portrays time through space no longer allows the reader to follow the action at his or her own pace. Innovation in both the webcomic and the print 
comic world often hinges on the way artists treat their panels - as O'Malley himself says,

some of the flashbacks will have lots of small panels. It's not even a density thing, but an alternate storytelling thing. [...] There's this one scene where they're watching a movie or something, and they're having an argument at the same time, and that had a lot of smaller panels - a faster rhythm like that. (McAlpin 2006)

Publishing decisions regarding a transition to digital comics are motivated by largely commercial concerns, in an attempt to satisfy as many consumers as possible. However, the industry is constantly second-guessing format and device use, and there still does not seem to be enough data to measure reading habits in order to make sound commercial decisions. In a survey conducted for the purposes of this article, $97.5 \%$ of respondents read webcomics, yet $61 \%$ did not read them on their phones - one response read that the screen was 'too tiny to appreciate the art'. However, one of the questions, which asked respondents to compare the smartphone reading experience to the print version, yielded some interesting answers. While no one found the reading experience superior, $31 \%$ found it on par with reading the print version, $52 \%$ found it inferior, but $5 \%$ found it 'too different to compare'. When asked to elaborate on why it was too different, one respondent wrote:

On Comixology, (an iPhone app) you have the option to read the comic panel-by-panel in a zoomed view, which is pretty much necessary on the small screen of a smartphone. This completely alters the pacing, because you view the story beat-by-beat. On paper, your eye can't help but take in the full 
page, even if you try not to read ahead. With the panel-by-panel view, every new panel is a surprise. This is not necessarily better or worse, but definitely different. (2011)

However, another respondent said, 'There is a forward momentum with Comixology's 'Guided View' system which made me much more of an active reader than I generally am when I read comics on paper' (2011). As the variety of responses demonstrate, the horizon of readerly expectations shifts with the reader's engagement with the digital mobile device, even though he or she might be reading the same content in print or onscreen. These shifts in perceptions of the text hold significant ramifications for the future of comics publishing and marketing as its products grow increasingly multimodal.

\section{Paracontexts, the app and the industry: Some conclusions}

Contemporary mainstream trade publishing, in a bid to stay relevant, is embracing the transmedia potential of narrative, especially with regard to digital platforms. However, as Michael Bhaskar notes, much of this multimedia output of publishers falls under the auspices of marketing such as book trailers, microsites and social networking campaigns. Bhaskar calls such output 'paracontent', describing it as

the emergent content that is part of a work, indeed fully integral to the rich experience of a work, yet disconnected from it; content that is encountered on platforms and in media different to the main work and which is purposed, to a large extent, as a marketing exercise to draw viewers into the main work. (2011: 26)

The previously discussed app, while fulfilling the requirements of being a component of 
transmedia storytelling by providing puzzle pieces to the narrative jigsaw of Scott Pilgrim's universe, does not really stand on its own as artefact, and, especially given the context of its commissioning (by Harper Collins on acquisition of the book rights), can be more accurately termed as paracontent, to use Bhaskar's term.

Different publishers are responding to this crucial moment in different ways - and it is not the independent publishers who are struggling. Both Marvel and its major rival DC are looking to revive the comic book heyday that defined their business from the 1960s to the late 1990s, while acutely aware that the most important factor in that success was the bricks and mortar comic book store, whose existence is ever-precarious after the coming of Amazon and online bookselling. Marvel, home to the X-Men and Spiderman, bounced back from its bankruptcy in 1997 on the strength of its reinvention as an intellectual property holding company, but still has to develop a sound digital strategy that will not alienate older readers yet will still attract new readers. Their much-vaunted 'motion comics' confused consumers by treading a fine line between animation and static sequential art, and were considered over-priced compared to print comics.

$\mathrm{DC}$, in a quest to grow new readers, have recently rebooted their business by offering same-day digital and print release of a new universe of superheroes, starting from Volume \#1. DC's hope is clearly to attract a generation of comic readers who have already been primed by the recent spate of comic book films, but assuming that these readers will be happy to pay the same price for print and digital on release. While this does solve the quandary of undercutting print prices, consumers are less than happy with the situation given that the Internet has fostered a universal expectation for free content, or close to free. As a point of comparison, runaway success app Angry Birds costs 99 
cents, while each issue of a digital DC download costs $\$ 2.99$.

Göran Bolin theorizes that the 'tangible carrier' of content, such as a DVD, or comic book, no longer has the same value, as its content can now be digitally liberated whatever the original format (2011). Scott McCloud's prescient declaration 'For music, art, movies, comics and the written word, our whole planet is about to become one giant jukebox' (2000: 189) articulates how once the specificity of the tangible carrier is dispersed, all cultural expressions are on par with one another. Intangible content now enters into economic circulation as a 'sign commodity', making the 'system more reliant on the means of consumption' (Bolin 2011: 106). It is precisely this phenomenon that will valorize the material specificity of the comic, as any challenge to the artefact posed by remediation interrogates the very notion of the comic's ontology, positively answering McCloud's question 'Will comics lose their magic if we can no longer touch them?' (2000: 177).

Commercially speaking, however, the unmooring of content from analogue devices means that media properties grow ever more slippery and elusive, and can only be viable if locked down with some form of intellectual property protection, such as digital rights management. While the potential of intangible content can only be realized by publishers if they own the rights to these properties, Bolin points out that the media industries exploit these rights in addition to the 'primitive accumulation' of audiencegenerated content on social networking websites, etc. (2011: 112). However, Jenkins' theorization of 'participatory culture' puts a positive spin on such audience engagement that belies passive consumption and creates 'prosumers' instead - consumers who also create and share content in response to a cultural artefact - arguing that it fosters 
creativity and a sense of community. The Scott Pilgrim microsite by Oni Press exemplifies the tension between these two opinions - its 'media' section features various examples of fan artwork, many of which are not attributed to the original artists. No fan can benefit in any way financially from this display, as 'Scott Pilgrim' is trademarked, thus granting contributors only the sign value of prestige and possibly, very briefly, fame.

The comic's nostalgic preoccupation with old technologies such as eight-bit gaming and arcade games betrays an anxiety regarding format irrelevance and obsolescence, as well as about big business and media conglomeration - it is no coincidence that Gideon Graves, Scott's ultimate nemesis, and leader and founder of the League of Evil Exes, heads 'GGG Heavy Industries' and is portrayed as a ruthless music mogul. As is evident from this article, Scott Pilgrim is clearly a product of media convergence, though, significantly, this convergence is not under the aegis of a single media institution. Interestingly, despite the participation of a major studio like Universal, no one media producer alone owns the intellectual property, and the properties of each medium contribute to creating the commercial success of the property. The comic itself enacts the difficulties of maintaining artistic and personal integrity in the face of financial temptation. As the comic book industry becomes increasingly dominated by a drive to create transmedia properties that may be used in the service of paracontent, individual comic creators will find it difficult to succeed in isolation and will need to cautiously embrace the possibilities of working together with publishers, while ensuring they protect themselves contractually. Higher royalty shares afforded by the digital publishing economy will hopefully allow this hybrid business model to thrive, and allow both artists and the industry, like the indomitable Scott Pilgrim, to experience their finest hour. 


\section{References}

Bhaskar, M. (2011), 'Towards paracontent: marketing, publishing and cultural form in a digital environment', Logos, 22:1, pp. 25-36.

Bolin, G. (2011), Value and the Media: Cultural Production and Consumption in Digital Markets, Surrey: Ashgate Publishing.

Genette, G. ([1997] 2007), Paratexts: Thresholds of Interpretation (trans. J. E. Lewin), Cambridge: Cambridge University Press.

Grainger, J. (2010), 'Come on, Pilgrim: The ultimate Scott Pilgrim map', The Excerpt, July $21_{\Delta}^{\text {st }}$. http://theexcerpt.com/2010/07/come-on-pilgrim-the-ultimate-scott-pilgrim-

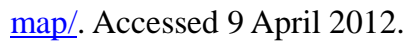

Hudson, L. (2010), “'Scott Pilgrim’s Finest Hour” arrives for Bryan Lee O’Malley”, interview, http://www.comicsalliance.com/2010/07/20/scott-pilgrims-finest-hour-bryanlee-omalley/\#ixzz1s4jyLhhg. Accessed 8 April 2012. 
Jenkins, H. (2006a), Fans, Bloggers, and Gamers: Exploring Participatory Culture, New York, NY: New York University Press. (2006b), Convergence Culture: Where Old and New Media Collide, Kindle version, New York, NY: New York University Press. Accessed 31 May 2012.

(2007), 'Transmedia storytelling 101', Confessions of an Aca-Fan, 22 March, http://www.henryjenkins.org/2007/03/transmedia_storytelling_101.html. Accessed 7 April 2012.

McAlpin, G. (2006), ‘An interview with Bryan Lee O’Malley’, http://www.gordonmcalpin.com/writing/interview-bryanomalley.html. Accessed 8 April 2012.

McCloud, S. (2000), Reinventing Comics: How Imagination and Technology are Revolutionizing an Art Form, New York, NY: Harper Collins. (2009), 'The "Infinite Canvas"”, http://scottmccloud.com/4inventions/canvas/index.html. Accessed 14 April 2012.

O’Malley, B. L. (2003), 'Zippy-zip'. http://www.flickr.com/photos/radiomaru/945015436/in/set-72157605071254206/. Accessed 10 April 2012. (2004), Scott Pilgrim: Precious Little Life, vol. 1, Portland: Oni Press. (2005), Scott Pilgrim vs. The World, Portland: Oni Press. (2006), Scott Pilgrim \& The Infinite Sadness, vol. 3, Portland: Oni Press. (2007a), Scott Pilgrim Gets It Together, vol. 4, Portland: Oni Press. (2007b), The Annotated Pilgrim: Notes on the Scott Pilgrim Series, Toronto: TCAF. 
(2009), Scott Pilgrim vs. The Universe, vol. 5, Portland: Oni Press.

(2010), Scott Pilgrim's Finest Hour, vol. 6, Portland: Oni Press.

(2012), 'Prehistory', Radiomaru, n.d., http://www.radiomaru.com/info/info-

prehistory.html. Accessed 10 April 2012.

Pearce, C. (2002), 'Story as play space: Narrative in games’, L. King (ed.), Game On:

The History and Culture of Videogames, London: Laurence King Publishing Ltd, pp.

$112-19$.

Pique, H. (2011), 'Discussion regarding the creation of the 'Scott Pilgrim' app for Harper

Collins', Skype conversation, personal communication, 12 July.

Reinerth, M. S. (2011), 'No story is an island: Storyworlds across media', Journal of

Literary Theory Online: Conference Proceedings,

http://www.jltonline.de/index.php/conferences/article/view/421/1123. Accessed 8 April

2012.

Richards, M. (2011), 'Discussion regarding the acquisition of rights to "Scott Pilgrim" for Fourth Estate, phone conversation, personal communication, 11 July 2011.

Modern Tales (2012), 'Modern Tales', http://www.moderntales.com/subscribe.php.

Accessed 8 April 2012.

Tabor, D. (2010), 'An EPIC conversation with Edgar Wright \& Michael Cera of Scott

Pilgrim Vs. The World', Geekadelphia, http://geekadelphia.com/2010/08/16/an-epic-

conversation-with-edgar-wright-michael-cera-of-scott-pilgrim-vs-the-world/. Accessed 8

April 2012.

The Beat (2010), 'Scott Pilgrim's finest sales chart: 1 million in print', The Beat, http://www.comicsbeat.com/2010/09/17/scott-pilgrims-finest-sales-chart-1-million-in- 
print/. Accessed 7 April 2012.

Thoss, J. (2011), 'Media rivalry updated: The case of Scott Pilgrim', Storyworlds Across Media, Johannes Gutenberg-University, Mainz, 30 June-2 July.

Wright, E. (2007), Scott Pilgrim vs. the World, UK: Universal Pictures.

Various (2011), 'Reading digital comics', Survey Monkey,

http://www.surveymonkey.com/s/CDPJHZG. Accessed 14 April 2012.

\section{Contributor details}

Dr Padmini Ray Murray teaches publishing studies at the University of Stirling. She is on the advisory board for Graphic Scotland, an organization dedicated to promoting comics and graphic novels in Scotland. She is particularly interested in the impact of digital technologies on publishing, reading and authorship.

Contact:

Dr Padmini Ray Murray, Lecturer, Publishing Studies, Stirling Centre for International Publishing and Communication, School of Arts and Humanities, Room B1, Pathfoot Building, University of Stirling FK9 4LA

E-mail: padmini.raymurray@stir.ac.uk

Note

${ }^{1}$ Innocence and the blossoming of adolescence are themes very commonly treated in genres such as shojo and shonen manga (manga for young girls and young boys, respectively), which are popular with adult audiences as well as younger readers. 